\title{
Techniques of Hepatic Transection in Robotic Surgery - Is there Still Scope for Improvement?
}

\author{
Thakkar R*, Kanwar A, Alessandri Gr, Sen G, French J, Manas D and White SA \\ Department of Hepatobiliary and transplant surgery, Freeman hospital, United Kingdom
}

Submission: June 26, 2018; Published: August 20, 2018

"Corresponding author: Thakkar R, Department of Hepatobiliary and transplant surgery, Freeman hospital, Newcastle upon Tyne, United Kingdom; Email: rohan.thakkar@nuth.nhs.uk

Abbreviations: CUSA: Cavitron Ultrasonic Surgical Aspirator; UD: Ultrasonic Dissector; LLR: Laparoscopic Liver Resection; RALS: Robot Assisted Liver Surgery

\section{Introduction}

More than 2000 major and minor liver resections were done in the United Kingdom during 2016-17, [1] a long way since 1886, when Dr. Luis had the first attempt at liver resection [2].

Technological advances have helped dramatically in developing various strategies for resecting the liver. Hospital mortality rate of hepatic resection are around 5\% depending on the size of the resection, for small resections mortality is even lower between $0-1 \%$ in specialized centers [3-8]. The development of specific instruments for liver transection, such as the ultrasonic dissector (CUSA), Water Jet, Harmonic Scalpel, Ligasure, Staplers, LOTUS torsion, and the Tissue-Link dissecting sealer have all shown to reduce risk and blood loss $[9,10]$.

There have been several randomized controlled trials and systematic reviews looking at the safety and efficacy of many techniques and technologies used for hepatic resection [1113]. These developments have also occurred alongside the development of minimally invasive techniques. Laparoscopy for liver resection was first documented in the early 1990s, proving over the years to be as safe as conventional open hepatectomy whilst still retaining oncologic integrity [14-20]. However, the disadvantages of laparoscopy are well documented such as limited instrument motion, unstable camera platforms and poor ergonometry and by less experienced operators the ability to stop rapid bleeding; all factors that have undoubtedly hindered its widespread use to match the operative complexity and dexterity that is much easier during open hepatobiliary surgery [21-23]

The Da Vinci-Si Surgical System (Intuitive Surgical, Sunnyvalle, CA, USA) provides surgeons with intuitive translation from the instrument handle to fine movements of the tip, eliminating the mirror-image effect. In addition, a remotely controlled camera provides improved visualization with highquality 3-dimensional images and a stable camera platform with scaling, tremor filtering, and coaxial alignment of the eyes and EndoWrist, with a $360^{\circ}$ range of motion, allowing more precise operating techniques [24-31]. The Da Vinci Xi system also allows the potential for different camera positions that are extremely useful for multiple resections when tumors are present in different liver segments/lobes.

In this article we discuss the current techniques of Hepatic transection and applicable to Robotic Hepatic Surgery.

\section{Techniques of Hepatic Transection}

\section{Finger/clamp fracture (Kelly Clasia)}

The finger fracture technique, which involves crushing of the liver parenchyma by fingers under inflow occlusion to isolate vessels and bile ducts for ligation, was first introduced by Lin et al. in 1958 [32]. This technique was subsequently improved through the use of surgical instruments such as a small Kelly clamp for blunt dissection (clamp crushing) [33].

A randomized prospective study has evaluated 100 patients without cirrhosis or cholestasis to liver resection using one of four methods: crush-clamp, ultrasonic dissector, water jet, or dissecting sealer. Those patients randomized to crush-clamp technique all underwent a Pringles maneuver (compression at the hepatoduodenal ligament) whereas this was not exclusively used with the other liver transection techniques. The crushclamp technique was associated with a shorter resection time, less blood loss, lower frequency of blood transfusion, and proved to be the most cost-effective method [34]. 
A Cochrane review failed to show any significant differences with regards to mortality, morbidity, markers of liver parenchymal injury, or ICU/hospital length of stay when comparing the crushclamp to alternative methods [13]. The review did show crushclamp to be faster and more cost effective $[10,13]$.

Unfortunately, the above-mentioned technique has a limited role in Robotic surgery and has been superseded by more superior energy devices.

\section{Water jet}

The water jet dissector (ERBEJET 2, ERBE USA Inc, Marietta, GA, USA) employs a pressurized jet of water instead of ultrasonic energy to fragment the liver parenchyma tissue exposing vascular and ductal structures. In open surgery the water jet has a nozzle diameter of $0.1 \mathrm{~mm}$ and a pressure of $30-40$ bar. The advantage of this thin, laminar liquid-jet effect includes precise, controllable, tissue-selective dissection with excellent visualization, and minimal trauma to surrounding fibrous structures. Volmer et al concluded that the Water-jet technique is relatively simple and easy to learn, for both the surgeons and the operative nursing staff and had a short learning curve [35].

Rau et al. retrospectively analyzed 350 liver resections using a water jet. They found the Water-jet to be significantly faster than the CUSA with less need for Pringle occlusion and fewer transfusions [36].

Currently the waterjet is not available on a robotic platform and can be used only in open and laparoscopic liver surgery

\section{Harmonic scalpel}

The Harmonic Scalpel (Ethicon Endo-Surgery, Cincinnati, $\mathrm{OH}, \mathrm{USA}$ ) uses ultrasound energy applied to vibrating ultrasonic shears to seal and divide blood vessels up to $3 \mathrm{~mm}$ in diameter. The vibration of the blades at 55,500 times per second simultaneously cuts and coagulates tissues by causing denaturization of proteins. This allows for a precise transection plane and reduces lateral thermal damage $(<1 \mathrm{~mm})$. In a non-randomized study, the use of the Harmonic Scalpel was associated with decreased operative time and a trend toward decreased blood loss and transfusion requirement. However, it was also associated with a significant increase in the incidence of postoperative bile leaks [37].

Although the harmonic scalpel is available on a robotic platform and is efficient in cutting and coagulating, it lacks the endowrist function (3600) and does not have all the degrees of freedom of other robotic tools. This limitation requires some adjustments during the procedure to align the instrument with the transection line [38].

\section{CUSA}

The Cavitron Ultrasonic Surgical Aspirator (CUSA, Tyco Healthcare, Mansfield, MA, USA) combines ultrasonic energy with aspiration to divide the liver parenchyma and thus skeletonize small parenchymal vessels and biliary structures greater than $2 \mathrm{~mm}$, which are then divided according to preference e.g. clipping or by an energy device.
CUSA can be used in cirrhotic as well as non-cirrhotic livers and is associated with a less blood loss and a lower risk of bile leaks [39]. The disadvantage of using CUSA is that it takes more time to transect the liver. Nonrandomized studies have shown decreased blood loss, morbidity, and mortality using CUSA, however, larger randomized trials have not shown this benefit over the traditional crush clamp method [40].

CUSA is widely used in open and laparoscopic liver surgery but is still not available for Robotic assisted liver resections. It can be used via the assistant port but will be limited by space due to robotic arms.

\section{Bipolar devices}

The Ligasure Vessel Sealing System (Covidien, Mansfield, MA, USA) is a bipolar vessel-sealing device that can permanently occlude blood vessels up to $7 \mathrm{~mm}$ in diameter by combining pressure and energy to fuse the collagen matrix in the vessel wall [41].

Two Japanese studies compared LigaSure to crush-clamp method, the former was associated with significantly lower blood loss, faster transection speed, and lower number of ties required. There were more bile leaks associated with Ligasure. None of the outcomes were statistically significant $[42,43]$.

A vessel sealer with combined cutting capability is available in Robotic surgery, but the liver parenchyma tends to shear whilst closing the jaws prior to cutting the parenchyma. It has dualhinged, thermally isolated jaws capable of sealing and cutting vessels of $7 \mathrm{~mm}$ caliber with lateral thermal damage confined to a perimeter of $1-2 \mathrm{~mm}$. It has independent seal and cut functions with user feedback and tremor filtration. The current instrument that is compatible with the robotic does have and endowrist which is advantageous.

\section{Staplers}

Various endoscopic staplers are available and used in liver surgery (Ethicon Endo-Surgery, Cincinnati, OH, USA or Covidien, Mansfiel). They can seal any unexpectedly injured bile ducts or blood vessels [44-46]. Transection of hepatic parenchyma with vascular staplers has been assessed, and its advantages include a low rate of biliary complications (i.e. bile fistulas and bilioma) and reduced bleeding [47].

The stapler can be used in liver surgery for control of inflow and outflow vessels, or to divide liver parenchyma. It is useful to transect hepatic veins (which lie deep in the liver parenchyma) and also the biliary pedicle. The preferred technique to divide the hepatic duct pedicle during hepatic transection instead of dividing the duct extra-hepatically to avoid leaving an ischemic stump of hepatic duct, which may increase the risk of biliary fistula. The use of a vascular stapler to divide the hepatic duct saves time from suturing. However, caution has to be taken not to narrow the hepatic duct confluence, especially during a right or left extended hepatectomy for a large tumor encroaching on the liver hilum, which leaves little room for application of the stapler. 
A retrospective series of greater than 200 patients over 10 years who underwent partial hepatectomy with either the crushclamp alone or vascular stapler techniques, found that compared to crush-clamp, use of a vascular stapler was associated with less operative time, blood loss, and transfusion requirements [48].

Finally, the CRUNSH trial is a newly designed prospective, randomized controlled trial comparing the efficacy of the crushclamp technique versus use of a vascular stapler for parenchymal transection [49]. The trial has not closed yet.

The robotic endovascular stapling devices are not licensed for hepatic transection. The laparoscopic device can be implemented with the help of an assistant and an assistant port.

\section{Radiofrequency devices}

This is a technique wherein a radiofrequency probe (Habib 4X, Angiodynamics, Queensbury, NY, USA) induces coagulative necrosis in a sphere of tissue around the probe to treat the parenchyma along the plane of dissection for a few seconds which pre-coagulates the tissues which is then cut with a scalpel. There is potential for heat sink and thermal injury to surrounding biliary radicles and vascular structures

A randomized trial from Italy compared radiofrequency assisted liver resection to crush-clamp and found a higher rate of postoperative complications (abscesses, biliary fistula, and biliary stenosis) in the radiofrequency-assisted group [9].

Tissuelink (Aquamantys) is another device that works using transcollation (transforming collagen) technology sealing small biliary radicals, no charring and gives a bloodless operating field. This device delivers radiofrequency energy and saline simultaneously to achieve temperatures of $100 \mathrm{oC}$. The major disadvantage is that is can be slower and is more expensive.

One randomized study showed that use of ultrasonic dissector (UD) combined with TissueLink is superior to UD combined with bipolar cautery in terms of reduced blood loss and faster transection speed with no increase in morbidity [50].

An expert panel opinion suggests that UD along with tissuelink was associated with a lower morbidity, lower transfusion rate and could eliminate the need for inflow occlusion [51].

At present, this method is not widely used in liver transection and is not compatible for use during robotic surgery, although the tissuelink could be used via an assistant port in adjunct to hepatic transection in robotic surgery.

\section{Discussion}

Liver surgery is now associated with less morbidity a mortality with the advent of new techniques in surgery. There is a trend towards minimally invasive approach as it has the advantage of less post-operative analgesia, reduced hospital stays, and similar outcomes shown compared to open surgery

At the end of 2008, a consensus conference on laparoscopic liver resection (LLR) was held in Louisville, Kentucky. During this conference, the criteria that are best suited for this kind of surgery were defined, including lesions that are solitary, $5 \mathrm{~cm}$ or less, located in peripheral segments 3-6 [52].

It remains to be determined if the robotic platform provides definitive advantages over standard laparoscopy in liver surgery. The data show significantly longer operating times for robot assisted liver surgery (RALS) over conventional laparoscopic liver resection (LLR). However, this finding is biased by the fact that the learning curve of robot-assisted laparoscopic liver resection had not been completed, as most series included here represent initial experience. As was shown by Tsung et al., operating time, blood loss and length of stay significantly decrease as experience grows [53].

A few centers have published results from their initial experience on RALS with good outcomes [54-56]. A retrospective analysis of laparoscopic and robotic surgeries in Taiwan concluded that they had similar outcomes although the major hepatectomy rate increased from 15 to $44 \%$ when they adopted RALS [57]. To aid in making RALS safer, novel applications such as indocyanine-green biliary contrast (FireFly imaging) and integrated augmented-reality navigation have been used in concordance. The former needs the aid of near infra-red fluorescence to identify biliary and vascular anatomy, reducing the chances of intra operative complications.

One of the limits of robotic HPB surgery is the need for specialized training, not only for the primary surgeon, but also for the assistant surgeon and OR nurses, although in some cases, the learning curve for specific robotic procedures has proven to be shorter than the laparoscopic equivalent.

\section{Conclusion}

RALS is a feasible procedure. A current problem is that there are a limited number of robotic instruments for parenchymal transection. Yet, the CUSA system, widely used in open and laparoscopic liver surgery, is not available for the robotic platform. It also remains unclear which technique is best for parenchymal transection during robotic liver resection and a comparative study would be required.

\section{References}

1. Blumgart LH, Belghiti J (2007) Surgery of the liver, biliary tract, and pancreas. In: ( $4^{\text {th }}$ edn) Philadelphia, PA: Saunders Elsevier.

2. Belghiti J, Hiramatsu K, Benoist S, Massault P, Sauvenet A, et al. (2000) Seven hundred forty-seven hepatectomies in the 1990s: an update to evaluate the actual risk of liver resection. J Am Coll Surg 191(1): 38-46.

3. Jarnagin WR, Gonen M, Fong Y, De Matteo RP, Ben-Porat L, et al. (2002) Improvement in perioperative outcome after hepatic resection: analysis of 1,803 consecutive cases over the past decade. Ann Surg 236(4): 397-406.

4. Imamura H, Seyama Y, Kokudo N, Maema A, Sugawara Y, et al. (2003) One thousand fifty-six hepatectomies without mortality in 8 years. Arch Surg 138(11): 1198-1206.

5. Kooby DA, Stockman J, Ben-Porat L, Gonen M, Jarnagin WR, et al. (2003) Influence of transfusions on perioperative and long-term outcome in patients following hepatic resection for colorectal metastases. Ann Surg 237(6): 860-869. 
6. Poon RT, Fan ST, Lo CM, Liu CL, Lam CM, et al. (2004) Improving perioperative outcome expands the role of hepatectomy in management of benign and malignant hepatobiliary diseases: analysis of 1222 consecutive patients from a prospective database. Ann Surg 240(4): 698-708.

7. Marvin MR, Buell JF (2009) Laparoscopic Liver Surgery. Adv Surg 43(1): 159-173.

8. Lupo L, Gallerani A, Panzera P, Tandoi F, Di Palma G, et al. (2007) Randomized clinical trial of radiofrequency-assisted versus clampcrushing liver resection. Br J Surg 94(3): 287-291.

9. Lesurtel M, Selzner M, Petrowsky H, McCormack L, Clavien PA (2005) How Should Transection of the Liver Be Performed? A Prospective Randomized Study in 100 Consecutive Patients: Comparing Four Different Transection Strategies. Ann Surg 242(6): 814-823.

10. Pamecha V, Gurusamy KS, Sharma D, Davidson BR (2009) Techniques for liver parenchymal transection: A meta-analysis of randomized controlled trials. HPB 11(4): 275-281.

11. Gagner MRM, Dubuc J (1992) Laparoscopic partial hepatectomy for liver tumor. Surg Endosc 6: 97-98.

12. Gurusamy KS, Pamecha V, Sharma D, Davidson BR (2009) Techniques for liver parenchymal transection in liver resection. Cochrane Database Syst Rev (1): CD006880.

13. Wayand W, Woisetschlager R (1993) Laparoscopic resection of liver metastasis. Chirurg 64(3): 195-197.

14. Simillis C, Constantinides VA, Tekkis PP, Darzi A, Lovegrove R, et al (2007) Laparoscopic versus open hepatic resections for benign and malignant neoplasms-a metaanalysis. Surgery 141(2): 203-211.

15. Buell JF, Thomas MT, Rudich S, Marvin M, Nagubandi R, et al. (2008) Experience with more than 500 minimally invasive hepatic procedures. Ann Surg 248(3): 475-486.

16. Bryant R, Laurent A, Tayar C, Cherqui D (2009) Laparoscopic liver resection-understanding its role in current practice: the Henri Mondor Hospital experience. Ann Surg 250(1): 103-111.

17. Nguyen KT, Gamblin TC, Geller DA (2009) World review of laparoscopic liver resection-2,804 patients. Ann Surg 250: 831-841.

18. Kitisin K, Packiam V, Bartlett DL, Tsung A (2011) A current update on the evolution of robotic liver surgery. Minerva Chir 66(4): 281-293.

19. White SA, Satchidanand RY, Manas D (2011) Laparoscopic liver surgery In: Ahmed Abdel Raouf El Geidie (edt). Updated topics in minimally invasive abdominal surgery. Intech 87-112.

20. Milone L, Daskalaki D, Fernandes E, Damoli I, Giulianotti PC (2013) State of the art in robotic hepatobiliary surgery. World J Surg 37(12): 2747-2755.

21. Giulianotti PC, Coratti A, Sbrana F, Addeo P, Bianco FM, et al. (2011) Robotic liver surgery: results for 70 resections. Surgery 149(1): 29-39.

22. Panaro F, Piardi T, Cag M, Cinqualbre J, Wolf P, et al. (2011) Robotic liver resection as a bridge to liver transplantation. JSLS 15(1): 86-89.

23. Cadiere GB, Himpens J, Germay O, Izizaw R, Degueldre M, et al. (2001) Feasibility of robotic laparoscopic surgery: 146 cases. World J Surg 25(11): 1467-1477.

24. Giulianotti PC, Coratti A, Angelini M, et al. (2003) Robotics in general surgery: personal experience in a large community hospital. Arch Surg 138(7): 777-784.

25. Vibert E, Denet C, Gayet B (2003) Major digestive surgery using a remote-controlled robot: the next revolution. Arch Surg 138(9): 10021006.

26. Choi SB, Park JS, Kim JK, Hyung WJ, Kim KS, et al. (2008) Early experiences of robotic assisted laparoscopic liver resection. Yonsei Med J 49(4): 632-638
27. Patriti A, Ceccarelli G, Bartoli A, Spaziani A, Lapalorcia LM, et al. (2009) Laparoscopic and robot-assisted one-stage resection of colorectal cancer with synchronous liver metastases: a pilot study. J Hepatobiliary Pancreat Surg 16(4): 450-457.

28. Idrees K, Bartlett DL (2010) Robotic liver surgery. Hepatobiliary Surg Nutr 3(5): 288-294.

29. Chan OC, Tang CN, Lai EC, Yang GP, Li MK (2011) Robotic hepatobiliary and pancreatic surgery: a cohort study. J Hepatobiliary Pancreat Sci 18(4): 471-480.

30. Lai EC, Tang CN, Yang GP, Li MK (2011) Multimodality laparoscopic liver resection for hepatic malignancy-from conventional total laparoscopic approach to robot-assisted laparoscopic approach. Int J Surg 9(4): 324-328.

31. Lin TY, Tsu K, Mien C, Chen C (1958) Study on lobectomy of the liver. J Formosa Med Assoc 57: 742-749.

32. Lin TY (1974) A simplified technique for hepatic resection: the crush method. Ann Surg 180(3): 285-290.

33. Lesurtel M, Selzner M, Petrowsky H, McCormack L, Clavien PA (2005) How should transection of the liver be performed?: a prospective randomized study in 100 consecutive patients: comparing four different transection strategies. Ann Surg 242(6): 814-822.

34. Vollmer CM, Dixon E, Sahajpal A, Cattral MS, Grant DR, et al. (2006) Water-jet dissection for parenchymal division during hepatectomy. HPB 8(5): 377-385.

35. Rau HG, Wichmann MW, Schinkel S, Buttler E, Pickelmann S, et al (2001) Surgical techniques in hepatic resections: Ultrasound Aspirator versus Jet-Cutter. A prospective randomized trial. Zentralbl Chir 126(8): 586-590.

36. Kim J, Ahmad SA, Lowy AM, Buell JF, Pennington LJ, et al. (2003) Increased biliary fistulas after liver resection with the harmonic scalpel. Am Surg 69(9): 815-819.

37. Giulianotti PC, Bianco FM, Daskalaki D, Gonzalez-Ciccarelli LF, Kim J, et al. (2016) Robotic liver surgery: technical aspects and review of the literature. Hepatobiliary Surg Nutr 5(4): 311-321.

38. Poon RT (2007) Current techniques of liver transection. HPB (Oxford) $9(3): 166-173$.

39. Fan ST, Lai EC, Lo CM, Chu KM, Liu CL, et al. (1996) Hepatectomy with an ultrasonic dissector for hepatocellular carcinoma. Br J Surg 83(1): 117-120.

40. Saiura A, Yamamoto J, Koga,R, Seki M, Yamaguchi T (2008) Liver transection using the LigaSure sealing system. HPB (Oxford) 10(4): 239243.

41. Saiura A, Yamamoto J, Koga R, Sakamoto Y, Kokudo N, et al. (2006) Usefulness of LigaSure for liver resection: analysis by randomized clinical trial. Am J Surg 192(1): 41-45.

42. Ikeda M, Hasegawa K, Sano K, Imamura H, Beck Y, et al. (2009) The vessel sealing system (LigaSure) in hepatic resection: a randomized controlled trial. Ann Surg 250(2): 199-203.

43. Fong Y, Blumgart LH (1997) Useful stapling techniques in liver surgery. J Am Coll Surg 185(1): 93-100.

44. Jurim O, Colonna JO, Colquhoun SD, Shaked A, Busuttil RW (1994) A stapling technique for hepatic resection. J Am Coll Surg 178: 510-511.

45. Raoof M, Aloia TA, Vauthey JN, Curley SA (2014) Morbidity and mortality in 1,174 patients undergoing hepatic parenchymal transection using a stapler device. Ann Surg Oncol 21: 995-1001.

46. Schemmer P, Friess H, Dervenis C, Schmidt J, Weitz J, et al. (2007) The use of endo-GIA vascular staplers in liver surgery and their potential benefit: a review. Dig Surg 24(4): 300-305. 
47. Reddy SK, Barbas AS, Gan TJ, Hill SE, Roche AM, et al. (2008) Hepatic parenchymal transection with vascular staplers: a comparative analysis with the crush-clamp technique. Am J Surg 196(5): 760-767.

48. Rahbari NN, Elbers H, Koch M, Bruckner T, Vogler P, et al. (2011) Clamp-crushing versus stapler hepatectomy for transection of the parenchyma in elective hepatic resection (CRUNSH)-a randomized controlled trial. BMC Surg 11: 22.

49. Arita J, Hasegawa K, Kokudo N, Sano K, Sugawara Y, et al. (2005) Randomized clinical trial of the effect of a saline-linked radiofrequency coagulator on blood loss during hepatic resection. Br J Surg 92(8): 954-959.

50. Manas DM, Figueras J, Azoula D, Valdecasas JC, French J, et al. (2016) Expert opinion on advanced techniques for hemostasis in liver surgery. European Journal of Surgical Oncology 42(10): 1597-1607.

51. Buell JF, Cherqui D, Geller DA, O Rourke N, Iannitti D, et al. (2009) The international position on laparoscopic liver surgery: The Louisville Statement, 2008. Ann Surg 250(5): 825-830.

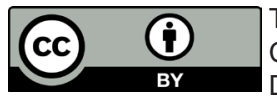

This work is licensed under Creative Commons Attribution 4.0 License

DOI: 10.19080/ARGH.2018.10.555781
52. Tsung A, Geller DA, Sukato DC, Sabbaghian S, Tohme S, et al. (2014) Robotic versus laparoscopic hepatectomy: a matched comparison. Ann Surg 259(3): 549-555.

53. Goja S, Singh MK, Soin AS (2017) Robotics in hepatobiliary surgery-initial experience, first reported case series from India. Int J Surg Case Rep 33: 16-20.

54. Reggiani P, Antonelli B, Rossi G (2013) Robotic surgery of the liver: Italian experience and review of the literature. E cancer medical science $7(1): 1-13$.

55. Kandil E, Noureldine SI, Saggi B, Buell JF (2013) Robotic Liver Resection: Initial Experience with Three-Arm Robotic and Single-Port Robotic Technique. JSLS 17(1): 56-62.

56. Wu YM, Hu RH, Lai HS, Lee PH (2014) Robotic-assisted minimally invasive liver resection Asian J Surg 37(2): 53-57.

57. Ocuin LM, Tsung A (2015) Robotic liver resection for malignancy: Current status, oncologic outcomes, comparison to laparoscopy, and future applications. J Surg Oncol 112(3): 295-301.

\section{Your next submission with JuniperPublishers will reach you the below assets}

- Quality Editorial service

- Swift Peer Review

- Reprints availability

- E-prints Service

- Manuscript Podcast for convenient understanding

- Global attainment for your research

- Manuscript accessibility in different formats

( Pdf, E-pub, Full Text, audio)

- Unceasing customer service

Track the below URL for one-step submission https://juniperpublishers.com/online-submission.php 